\title{
CHANGES IN HOMESTEAD BIODIVERSITY WITH MODERNIZATION IN THE RURAL AREAS OF BANGLADESH
}

\author{
M.R. Islam", M.A. Baten², S.M.A. Hossain ${ }^{3}$, S.M. Afroz ${ }^{\mathbf{4}}$ and K. Naher ${ }^{\mathbf{5}}$ \\ Received 3 March 2017, Revised 20 May 2017, Accepted 26 June 2017, Published online 30 June 2017
}

\begin{abstract}
A study was carried out at selected villages in Gazipur district of Bangladesh during 20082009 with a view to assess the changes in homestead biodiversity with degree of modernization in the rural areas. Three villages were selected purposively considering their degree of modernization e.g. traditional, semi-modern and modern village and biodiversity at 40 randomly selected homesteads from each of the three villages were studied. Species richness, interspecies diversity (Shannon-Wiener diversity index) and species evenness were considered for measuring the biodiversity. A total of 188 plant species belonging to 75 different families were identified in the homesteads of three study villages. The highest proportion (11\%) of species found under the family Gramineae followed by Cucurbitaceae (6\%), Compositae (5\%), Solanaceae (5\%), Leguminosae (4\%), Amaranthaceae (4\%), Rutaceae (3\%), Euphorbiaceae (3\%), Convolvulaceae (3\%), and Cyperaceae (3\%) and so on. Among the 188 plant species, $15 \%$ fruits species, $9 \%$ timber, $11 \%$ ornamental and medicinal, $14 \%$ vegetables, $4 \%$ spices and $47 \%$ weed species. The highest number (172) of species was found in traditional village and the lowest (126) in the modern village. Diversity index $(\mathrm{H})$ value for traditional village (1.652) was statistically similar to semi-modern village (1.373) but significantly higher $(t=2.47 *)$ than that of modern village $(1.029)$. So, it can be said that plant biodiversity is decreasing with increase in modernization and/or urbanization. The diversity $(\mathrm{H})$ decreased with decrease in farm size, in other words, species diversity increased with increase in farm size but there was no significant difference among the farm categories in this regard. The total evenness values against the three villages $(0.741,0.630$ and 0.491 in Bhawal Gazipur, Hatiyabo and Mariali, respectively) indicate that the abundance of different species was very dissimilar and decreased with increase in modernization.
\end{abstract}

Keywords: Biodiversity, Homestead, Rural Area, Modernization

\footnotetext{
${ }^{1}$ Principal Scientific Officer, On-Farm Research Division (OFRD), BARI, Gazipur 1701, Bangladesh

${ }^{2}$ Professor, Department of Environmental Science, Bangladesh Agricultural University, Mymensingh, Bangladesh

${ }^{3}$ Professor, Department of Agronomy, Bangladesh Agricultural University, Mymensingh, Bangladesh

${ }^{4}$ Lecturer, Department of Botany, Govt. B. L. University College, Daulatpur, Khulna, Bangladesh

${ }^{5}$ Senior National Technical Advisor, ECTAD, FAO of the United Nations, Bangladesh

*Corresponding author's email: mrafiqulislam62@yahoo.com (M.R. Islam)
}

\section{Introduction}

Gazipur is one of the nearest districts to the capital city Dhaka, Bangladesh where urban development, i.e. modernization has been taking place at a faster rate and in a diverse manner. The district has a large number of national establishments such as Bangabandhu Sheikh Mujibur Rahman Agricultural University (BSMRAU), International University of Technology (IUT), National University, Open University, Bangladesh Agricultural Research Institute (BARI), Bangladesh Rice Research Institute (BRRI), Dhaka University of Engineering and Technology (DUET), Security Printing Press, Machine Tools Factory, Ordnance Factory and many other important institutions/organizations. Biodiversity in the area is decreasing at an alarming rate due to acquisition of lands for such establishments and flourishing urbanization. Importance of the district has increased manifolds because of its strategic position after construction of the Jamuna Bridge over the river Jamuna to link northern districts with the capital city. Population and infrastructures have been growing rapidly and remarkably in the district since 90's. Moreover, environment of the district is at threat due to establishment of huge number of modern residential areas and different kinds of industries such as, garments, poultry, leather, chemicals, etc. The area of modern homesteads are becoming small to smaller day by day with no or little vegetation that affecting livelihood as well as biodiversity. Homestead plays a vital role for the existence of rural people, providing them with food, fuel, fodder, timber, fish and shelter. Homestead production is the most significant system of livelihood in rural Bangladesh (Halim et al., 1996). Its management affects the production, consumption, sale and repurchase of field crops, livestock, fishes, fruits, fuels, etc. The rural economy thus depends on productivity of the natural resources, which is intimately linked with the biodiversity in the ecosystem (Rahman et al., 2009). Considering the situation as mentioned above, a study deemed necessary to assess the changes in homestead biodiversity with degree of modernization in the rural areas. 


\section{Materials and Methods}

The study was carried out during 2008-2009 and Gazipur Sadar upazila of Gazipur district in Bangladesh was selected purposively for this piece of study. In particular, three villages of Gazipur Sadar upazila namely, Bhawal Gazipur (traditional village) and Hatiyabo (semi-modern village) under Kaultia Union and Mariali (modern village) under Gazipur Paurasava (municipality) constituted the study area. The degree of modernization of these villages was determined in terms of the availability of social institutions, literacy rate, public welfare services, infrastructural facilities, agricultural modernization, and settlement status. The distance from Gazipur town, universities or research institutions was also considered in this regard. Data were collected from samples, selected following a proportionate stratified random sampling technique. A village-wise list of households according to the farm categories (i.e. medium, small and landless) was prepared first. Then heads of households were selected randomly and proportionately at the ratio of 1:3:4 from medium (1.01-3.00 ha), small (0.21-1.0 ha) and landless (0.01-0.2 ha) farms, respectively, following the prevailing distribution of different farm size categories. There was no large farm (above $3.00 \mathrm{ha}$ ) household in any of the three villages. An equal number of samples were taken from each of the three villages. Thus, a total of 120 household heads (40 from each of the three villages) constituted sample of the study. In the present study, homestead biodiversity was evaluated considering mainly the plants and domestic animals. Following measures were used in determining the biodiversity.

i. Species richness $(\mathrm{S})=$ The number of species within a homestead

ii. Inter species diversity $(\mathrm{H})=-\operatorname{Sum}\left(\mathrm{P}_{\mathrm{i}}\right.$ $\left.\log \left[\mathrm{P}_{\mathrm{i}}\right]\right)$

Where, $\mathrm{H}=$ Shannon-Wiener index for diversity

$P_{i}=$ No. of individuals of one species divided by total no. of

iii. Species evenness $=\mathrm{E}=\mathrm{H} / \log (\mathrm{S})$

Where, $\mathrm{E}=$ Species evenness index

$\mathrm{S}=$ Species richness

$\mathrm{H}=$ Shannon-Wiener index

\section{Results and Discussions}

The existing biodiversity in the rural homesteads of selected villages of Gazipur Sadar upazila is described under - i) Species richness; ii) Inter species diversity and iii) Species evenness as follows:

\section{Species richness in the rural homesteads}

Almost all the homesteads of the study villages contained mixed vegetation of various annual and perennial plants including trees, shrubs and herbs. There were different types of domestic and pet animals and fishes in the ponds but not present in all the homesteads. Findings of the study showed that there were wide variety of plant and animal species in the homesteads and their number varied from one homestead to another and varied among the three study villages.

Plant species richness in the homesteads

A total of 188 plant species belonging to 75 different families were identified in the three study villages. The highest proportion (11\%) of species found under the family Gramineae followed by Cucurbitaceae (6\%), Compositae $(5 \%)$, Solanaceae $(5 \%)$, Leguminosae $(4 \%)$, Amaranthaceae (4\%), Rutaceae (3\%), Euphorbiaceae (3\%), Convolvulaceae (3\%), and Cyperaceae (3\%) and so on. Among the 188 plant species, $15 \%$ fruits species, 9\% timber, $11 \%$ ornamental and medicinal, 14\% vegetables, $4 \%$ spices and $47 \%$ weed species (Table 1). The highest number (172) of species was found in Bhawal Gazipur (traditional village) and the lowest (126) in the modern village Mariali (Table 1). It indicates that number of species decreased with increase in modernization of the villages. Particularly the number of weed species decreased remarkably in the modern village. However, the richness of other species i.e. fruits, timber, medicinal/ornamental, vegetable and spices were more or less same in the three selected villages. If only useful plant species are considered, there were 96 species including fruits, timber, vegetable, spices, medicinal and ornamental plants. Bashar (1999) identified 136 useful species in the homesteads of Gazipur district.

Table 1. Species richness of different plant groups in the homesteads of the study villages in Gazipur Sadar upazila.

\begin{tabular}{|c|c|c|c|c|c|c|c|}
\hline \multirow[t]{2}{*}{ Village } & \multicolumn{6}{|c|}{ No. of species } & \multirow[t]{2}{*}{ Total } \\
\hline & Fruit & Timber & $\begin{array}{l}\text { Medicinal/ } \\
\text { ornamental }\end{array}$ & Vegetables & Spices & Weeds & \\
\hline B. Gazipur & 29 & 14 & 13 & 26 & 6 & 84 & 172 \\
\hline Hatiyabo & 27 & 14 & 11 & 25 & 7 & 71 & 155 \\
\hline Mariali & 25 & 9 & 16 & 22 & 6 & 48 & 126 \\
\hline Average & 27 & 12 & 13 & 24 & 6 & 68 & 150 \\
\hline All & 29 & 16 & 20 & 27 & 8 & 88 & 188 \\
\hline & (15) & (9) & (11) & (14) & (4) & (47) & (100) \\
\hline
\end{tabular}

Figures in parentheses indicate percent 
Fruit: The number of fruits species was higher in the homesteads of selected villages compared to other categories of plant species except the weeds. Abedin and Quddus (1990) and Millat-e-Mustafa (1997) reported fruits as the prime component of homestead vegetation. Sellathurai (1997) also found that the number of fruit species was higher than other species in the homesteads of Kandy district in Sri Lanka. A total of 29 fruit species was recorded from three villages of Gazipur, the highest (29) in Bhawal Gazipur (traditional village) and the lowest (25) in Mariali (modern village). The number of fruit species also varied from one homestead to another. Bashar (1999) identified 44 fruit species while Mannan (2000) recorded 36 fruit species in the homesteads of Gazipur district. It indicates that fruit species in the homesteads decreasing over time.

Timber: Timber plants occupied fourth position with respect to average number of species and covered 9 percent of the total vegetation of rural homesteads (Table 1). Equal number of timber species (14) was recorded both at Bhawal Gazipur and Hatiyabo and the 13 common species were: auri, bhalka bamboo, ivy-rue, mahal bamboo, mahogany, eucalyptus, muli bamboo, raintree, sal, silk cotton, teak, and white siris. Another species 'paper tree' was found at Bhawal Gazipur while the species 'mangium' was found only at Hatiyabo. In mariali, the species like mangium, ivy-rue, malaria, mulli bamboo, paper tree, sal, sandpaper tree and silk cotton were not found at any homestead. Mannan (2000) recoded 30 timber species including species like, arjuna, kadam, red sandalwood, royal poinciana, neem, etc.

Medicinal and ornamental: A total of 20 species were identified from three selected villages (Table 1). These were mainly trees and shrubs such as arjuna, basil, black myrobalan, cape jasmine, china box, china rose, garden balsam, henna, jungle flame, kadam, love-liesbleeding, marigold, neem, night-blooming jasmine, paper flower, rose, royal poinciana, tube rose, water lily and yellow oleander. Only seven species found common over the three villages, which were: basil, henna, jungle flame, marigold, neem, rose and water lily. In addition to these seven common species, six other species found in Bhawal Gazipur were: arjuna, cape jasmine, kadam, love-lies-bleeding, tube rose and pigeon wings; there were four other species in Hatiyabo as: china box, china rose, night-blooming jasmine and Rangoon creeper, while nine other species recorded at Mariali were: black myrobalan, cape jasmine, china box, china rose, night-blooming jasmine, pigeon wings, tube rose, yellow-flame tree and yellow oleander. However, medicinal and ornamental plants constituted nine percent of the total plant species found in the homesteads.

Vegetable: With respect to average number of species, vegetables occupied $3^{\text {rd }}$ position among the plant groups and covered 14 percent of the total vegetation of the homestead (Table 1). A total of 27 vegetable species were identified of which 22 were common at all three selected villages which were: ash gourd, bitter gourd, brinjal, cucumber, lady's finger, Indian spinach, papaya, plantain, ribbed gourd, drum stick, sponge gourd, stem amaranth, teasel gourd, country bean, bottle gourd, radish, red amaranth, spinach, sweet gourd, taro and tomato. Five vegetables not recorded at Mariali were cabbage, cauliflower, snake gourd, yam and yardlong bean but these vegetables were present in Bhawal Gazipur and in Hatiyabo except cabbage.

Spices: Only eight species of spices were identified of which six were common over three selected villages and these were chili, coriander, garlic, ginger, onion and turmeric. Anise was found only in one homestead at Hatiyabo while bay leaf was found in one homestead at Mariali.

Weed: A total of 88 weed species were identified (Table 1) from three selected villages. Highest (84) number of weed species found in Bhawal Gazipur and the lowest (49) number of weeds was recorded at Mariali. Among the identified weed species, 46 found common in three selected villages were: Achiote, Bermuda grass, bitter dock, cocklebur, coat buttons, crow foot grass, dodder, dove weed, fathen, fern, fringed false pimpernel, gosmore), goose grass, harkuch, hill glory bower, Indian pennywort, Indian sorrel, ivy gourd, jersey cudweed, joint grass, keteli, lantana, leucas, love thorn, mazus, milk weed, nut sedge, para grass, pig weed, prickly amaranth, prickly chaff flower, prostate spurge, rush grass, sessile joyweed, sheand grass, malay blumea, swamp rice grass, Tex-Mex tobacco, touch-me-not, sessile joyweed, umbrella sedge, velvet leaf, water spinach, white eclipta, wild clary and wild pea.

\section{Richness of animal species}

Two livestock species i.e. cattle and goat were found in the homesteads of all three study villages. In the case of cattle, exotic or cross breed was found in many cases along with local breed. Black Bengal goat was the only species of goat (Table 2). Three poultry species as chicken, duck and pigeon were present in the study villages. Some exotic breeds found in case of chicken only. Only two pet animals e.g. dog and cat of local breed were found in some homesteads of all three villages. 
Table 2. Species richness of different animal groups in the homesteads of the study villages of Gazipur Sadar upazila.

\begin{tabular}{lcccccc}
\hline Village & \multicolumn{3}{c}{ No. of species } & \multirow{2}{*}{ Total } \\
\cline { 2 - 5 } & Livestock & Poultry & Pet animals & Fish* & Birds* & \\
\hline B. Gazipur & 2 & 3 & 2 & 24 & 21 & 52 \\
Hatiyabo & 2 & 3 & 2 & 21 & 20 & 48 \\
Mariali & 2 & 3 & 2 & 17 & 18 & 42 \\
Average & 2 & 3 & 2 & 21 & 19 & 47 \\
All & 2 & 3 & 2 & 28 & 21 & 56 \\
& $(4)$ & $(5)$ & $(4)$ & $(50)$ & $(37)$ & $(100)$ \\
\hline
\end{tabular}

* Number of fish and birds was determined by name of the species as mentioned by the respondents

Figures in parentheses indicate percent

Among the animals found in the homesteads, species richness was high in case of fishes. A total of 28 fish species were mentioned by the respondents which they observed recently in their ponds while catching fish. The species were as: badis dwarf, banded gourami, bronze featherback, catla, chanda, climbing perch, common carp, day's mystus, great snakehead, grass carp, Indian glassy fish, Indian river shad, mola carplet, Mozambique tilapia, mrigal, mirror carp, puntio barb, rohu, olive barb, small prawn, snakehead murrel, silver carp, stinging catfish, spotted snakehead, tank goby, ticto barb, walking catfish and yellowtail catfish. The highest number (24) of species was recorded at Bhawal Gazipur and the lowest (17) at Mariali (Table 2). In case of birds, respondents were asked to mention name of different birds as they observed in their homesteads during last one year. As much as 21 bird species (Table 2) mentioned by the respondents were: Asian koel, black capped oriole, black drongo, common myna, green bee- eater, house sparrow, hawk-cuckoo, jungle babler, kingfisher, magpie robin, owl, parakeet, pariah kite, pied myna, pond heron, raven, red whiskered bulbuli, spotted dove, sun bird, tailor bird and wood pecker. More or less similar species were recorded at Bhawal Gazipur and Hatiyabo while species like pond heron, kingfisher and owl were not recorded at Mariali.

\section{Inter species diversity and species evenness in the rural homesteads}

The species diversity index was computed following the Shannon-Wiener diversity index. Results presented in Table 3.1 and Table 3.2 showed that, species diversity varied with different farm categories and also among the selected villages. The species diversity index values 1.751, 1.729 and 1.644, respectively for medium, small and landless farms indicate that plant biodiversity was higher in all categories of farm (Table 3.1).

Table 3.1 Species diversity indices as affected by farm category in Gazipur Sadar upazila.

\begin{tabular}{llc}
\hline Farm category & Plant group & Diversity index $(\mathrm{H})$ \\
\hline Medium & Fruit & 0.921 \\
& Timber & 0.949 \\
& Medicinal/ ornamental & 0.833 \\
& Vegetables & 1.119 \\
Spices & 0.684 \\
Weeds & 1.523 \\
All & 1.751 \\
Fruit & 1.145 \\
& Timber & 0.918 \\
& Medicinal/ornamental & 0.712 \\
& Vegetables & 1.133 \\
& Spices & 0.760 \\
& Weeds & 1.407 \\
& All & 1.729 \\
& Fruit & 1.172 \\
& Timber & 0.648 \\
& Medicinal/ornamental & 0.634 \\
& Vegetables & 1.087 \\
& Spices & 0.623 \\
& Weeds & 1.344 \\
& All & 1.644 \\
\hline
\end{tabular}

The diversity $(\mathrm{H})$ decreased with decrease in farm positive consequence in between plant diversity size but there was no significant difference among and farm categories viz. it can be concluded that the farm categories in this regard. There is a plant diversity increased as the farm size 
increased proportionately (Rahman et al., 2009). Among the selected plant groups, diversity of weed species was the highest irrespective of farm categories followed by vegetables and the diversity was lowest with spices. It is notable that the diversity of fruit species increased with decrease in farm size i.e. diversity was highest with landless farms and lowest with medium farms. In fact, most of the landless households possessed only the homesteads where they grow some fruits and vegetables for own consumption or earn some money. Village-wise analysis of species diversity presented in Table 3.2 showed that diversity of plant species was higher in each of the villages. The diversity index $(\mathrm{H})$ values against each of the plant groups and the overall plant biodiversity index (1.832) indicates that plant biodiversity was higher in the area, while the evenness index (E) value of 0.808 indicates that the abundance of different plant species was somewhat dissimilar i.e. proportions of all the species were not similar over the area.
Considering all three villages together, diversity was the highest with fruits (1.679) followed in descending order by vegetable (1.556), weeds (1.416), timber (1.074), medicinal/ornamental plants (0.897) and spice (0.633). Bashar (1999) and Mannan (2000) found that diversity of fruit species was higher compared to other plant species in rural homesteads in Gazipur. Rahman et al. (2009) reported higher diversity of fruit species in the homesteads of southwestern districts Patuakhali and Barguna. Alam and Masum (2005) also found that number of fruit species was higher compared to other plant species in the homesteads of Sandwip. The reason might be that rural households like to grow food producing species in their homesteads for subsistence need and cash income. The total evenness values against the three villages (0.741, 0.630 and 0.491 in Bhawal Gazipur, Hatiyabo and Mariali, respectively) indicate that the abundance of different species was very dissimilar. Fruits and timber in Bhawal Gazipur and only fruits in Hatiyabo had similar abundance (Table 3.2).

Table 3.2 Species diversity of different plant groups in rural homesteads of the study villages in Gazipur Sadar upazila.

\begin{tabular}{|c|c|c|c|c|}
\hline Village & Plant group & Diversity index (H) & Evenness (E) & t-value \\
\hline Bhawal & Fruit & 1.452 & 1.003 & \\
\hline \multirow[t]{6}{*}{ Gazipur } & Timber & 1.206 & 1.052 & \\
\hline & Medicinal/ ornamental & 0.854 & 0.791 & \\
\hline & Vegetables & 1.348 & 0.953 & \\
\hline & Spices & 0.684 & 0.879 & $\mathrm{~B} \sim \mathrm{H}=1.02$ \\
\hline & Weeds & 1.529 & 0.859 & \\
\hline & Total & 1.652 & 0.741 & $\mathrm{~B} \sim \mathrm{M}=2.47^{*}$ \\
\hline \multirow[t]{7}{*}{ Hatiyabo } & Fruit & 1.384 & 0.978 & $\mathrm{H} \sim \mathrm{M}=1.46$ \\
\hline & Timber & 0.795 & 0.693 & \\
\hline & Medicinal/ ornamental & 0.713 & 0.685 & \\
\hline & Vegetables & 1.251 & 0.895 & \\
\hline & Spices & 0521 & 0.616 & \\
\hline & Weeds & 1.332 & 0.749 & \\
\hline & Total & 1.373 & 0.630 & \\
\hline \multirow[t]{7}{*}{ Mariali } & Fruit & 1.016 & 0.727 & \\
\hline & Timber & 0.591 & 0.619 & \\
\hline & Medicinal/ornamental & 0.633 & 0.538 & \\
\hline & Vegetables & 0.923 & 0.688 & \\
\hline & Spices & 0.378 & 0.486 & \\
\hline & Weeds & 0.845 & 0.503 & \\
\hline & Total & 1.029 & 0.491 & \\
\hline \multirow[t]{7}{*}{ All } & Fruit & 1.679 & 1.160 & \\
\hline & Timber & 1.074 & 0.892 & \\
\hline & Medicinal/ ornamental & 0.897 & 0.715 & \\
\hline & Vegetables & 1.556 & 1.087 & \\
\hline & Spices & 0.633 & 0.701 & \\
\hline & Weeds & 1.416 & 0.728 & \\
\hline & Total & 1.832 & 0.808 & \\
\hline
\end{tabular}

$\mathrm{B} \sim \mathrm{H}=$ Between Bhawal Gazipur and Hatiyabo; B $\sim \mathrm{M}=$ Between Bhawal Gazipur and Mariali; and $\mathrm{H} \sim \mathrm{M}=$ Between Hatiyabo and Mariali with respect to diversity index

The total plant biodiversity was higher in Bhawal Gazipur (traditional village) with an index value of 1.652 , which gradually decreased in Hatiyabo (semi-modern village) and Mariali (modern village) as shown in Table 3.2. The diversity index value against each plant group in Bhawal Gazipur was higher than other two villages. The t-test indicated that there was no significant difference 
between Bhawal Gazipur and Hatiyabo with respect to diversity of different plant groups $(\mathrm{t}$ $=1.018$ ) but there was significant difference between Bhawal Gazipur and Mariali $(\mathrm{t}=2.47 *$ ). So, the related null hypothesis is rejected in this case i.e. biodiversity in the rural homesteads decreased significantly with increase in modernization. Considering the species richness, species evenness of different species and the diversity index $(\mathrm{H})$, it can be said that plant biodiversity is decreasing remarkably with increase in modernization and/or urbanization. Some of the major reasons behind decrease in biodiversity in the modern village might be such that, higher percent of homesteads had been established recently ( 1 to 10 years), area of homesteads were smaller in size, major portion of the homesteads occupied by house and there was less area under vegetation. The fact that, process of urbanization increased highly in the villages adjacent to Gazipur district town over last decade particularly after construction of the Jamuna Bridge. Huge number of people already has migrated in Gazipur from other parts of the country mainly for job in large number of growing industries and in the government and non-government institutions/organizations. Accordingly, plenty of houses and other infrastructures have been constructed in the district town and its adjacent villages like Mariali for accommodating the increasing population. Local landlords have constructed houses for renting purposes while many of the migrated people and service holders have purchased small piece of land and constructed houses there. In this way, number of small homesteads increased remarkably in Mariali and such other villages in the district. The process is going on and in near future, modernization and urbanization will increase manifolds in the area. Croplands are converting into residential and industrial areas at an alarming rate. It is thus easily predictable that biodiversity will decrease significantly in Gazipur Sadar upazila particularly in villages adjacent to the district town. Hence, proper initiative is required from the concerned authority to preserve/protect decreasing species particularly the threatened species for maintaining a higher plant biodiversity for future generation. Side by side, people to be motivated for preserving such threatened plant species and growing a wide variety of plant species (including the lost species) in their homesteads in a planned manner so that they can harvest more benefit out of it.

\section{References}

Abedin, M.Z. and Quddus, A. 1990. Household fuel situation, home gardens and agroforestry practices at six agro-ecologically different locations of Bangladesh. In: Abedin, M.Z., Lai, C.K. and Ali, M.O. (eds.) Homestead Plantation and Agroforestry in Bangladesh, Proc. National Workshop held during July 17-19, 1988 in Joydebpur, Gazipur, Bangladesh. pp. 19-36.

Alam, M.S. and Masum, K.M. 2005. Status of Homestead Biodiversity in the Offshore Island of Bangladesh. Res. J. Agric. Bio. Sci. 1(3): 246-253.

Bashar, M.A. 1999. Homegarden Agroforestry: Impact on biodiversity conservation and household food security (A case Study of Gazipur District, Bangladesh). M. Sc. Thesis, Centre for Intl. Env. \& Dev. Stud., Noragic, Agril. Univ., Norway. pp. 21-34.

Halim, A., Hossain, M.A., Rahman, M.M., Alam, A.B.M.M., Hossain, S.M.A., Sobhan, M.A. and Islam, M.M. 1996. Management of homestead environment. Environment education training module for agricultural extension workers in Bangladesh. Graduate Training Institute, Bangladesh Agricultural University, Mymensingh. pp. 195-200.

Mannan, M. A. 2000. Plant-Biodiversity in the homesteads of Bangladesh and its utilization in crops improvement. Ph.D. Thesis, Department of Genetics and Plant Breeding, Bangabandhu Sheikh Mujibur Rahman Agricultural University, Salna, Gazipur. pp. 27-59.

Millat-e-Mustafa, M. 1997. Floristic and indigenous management techniques of home gardens in Bangladesh. In: Alam, M.K., Ahmed, F.U. and Amin, S.M.R. (eds.) Agroforestry: Bangladesh Perspective. Bangladesh Agricultural Research Council (BARC), Dhaka. pp. 34-67.

Rahman, M.M., Atiqullah, M. and Miah, M.G. 2009. Homestead Plant Biodiversity in the South-Western Costal Zone of Bangladesh: Way Forward to Identification, Utilization and Conservation. National Food Policy Capacity Strengthening Programme (NFPCSP). Food and Agric. Org. of United Nations (FAO), Dhaka, Bangladesh. pp. 1-25.

Sellathurai, P. 1997. Homestead Agroforestry and Sustainability in Kandy District, Sri Lanka. M.Sc. Thesis, Agril. Univ., Norway. 